\title{
The First Total Synthesis of Sphingofungin $E$ and the Determination of its Stereochemistry
}

Bing Wang, Xiao-ming Yu, Guo-qiang Lin*

Shanghai Institute of Organic Chemistry, Academia Sinica, 354 Fenglin Road, Shanghai, 200032, China

Fax +8621 64166263; E-mail: gqlin@ pub.sioc.ac.cn

Received 14 November 2000

Dedicated to Professor R. Noyori in appreciation of his great contribution to organic synthesis

\begin{abstract}
The total synthesis of sphingofungin E has been realized for the first time and its absolute configurations were established. Starting from L-(+)-tartaric acid, our synthesis featured substratecontrolled asymmetric dihydroxylation, regiospecific epoxide formation and Hatakeyama reaction to construct the contiguous chiral centers in the target molecule.
\end{abstract}

Key words: total synthesis, amino acids, dihydroxylations, Wittig reactions, epoxides

Sphingofungin E (1) and F (2), two new members of the sphingofungin family, were first isolated from the fermentation broth of Paecilomyces variotii by Merck's group in 1992. ${ }^{1}$ They showed significant biological activity in inhibiting serine palmitoyltransferase, and had antifungal activity against several human pathogenic fungi. ${ }^{1}$ They also bear structural resemblance to myriocin $(3),{ }^{2}$ a com- pound 10-100 times more potent than immunosuppressant cyclosporin A. ${ }^{3}$ Although there has been a number of works on the total synthesis and the absolute stereochemistry of $2,{ }^{4}$ the most highly oxygenated member of the family, sphingofungin E, remained untackled, and its stereochemistry was only tentatively assigned. ${ }^{1}$ As it is our continued interest in the synthesis of polyhydroxylamines and $\alpha$-substituted amino acids, we have undertaken the syntheses of both $\mathbf{1}$ and $2 .{ }^{5}$ Herein we report the first total synthesis of sphingofungin $\mathrm{E}$ and the determination of its stereochemistry.

Scheme 1 illustrates the retrosynthetic analysis. The target molecule could be disconnected into a known phosphonium salt $\mathbf{4}^{6}$ and a polar head 5 bearing four contiguous chiral centers. The C-2 configuration of $\mathbf{5}$ was expected to be established via intramolecular ring-opening of epoxide 6. ${ }^{7}$ The $\alpha, \beta$-epoxido ester structure unit of $\mathbf{6}$ was in turn

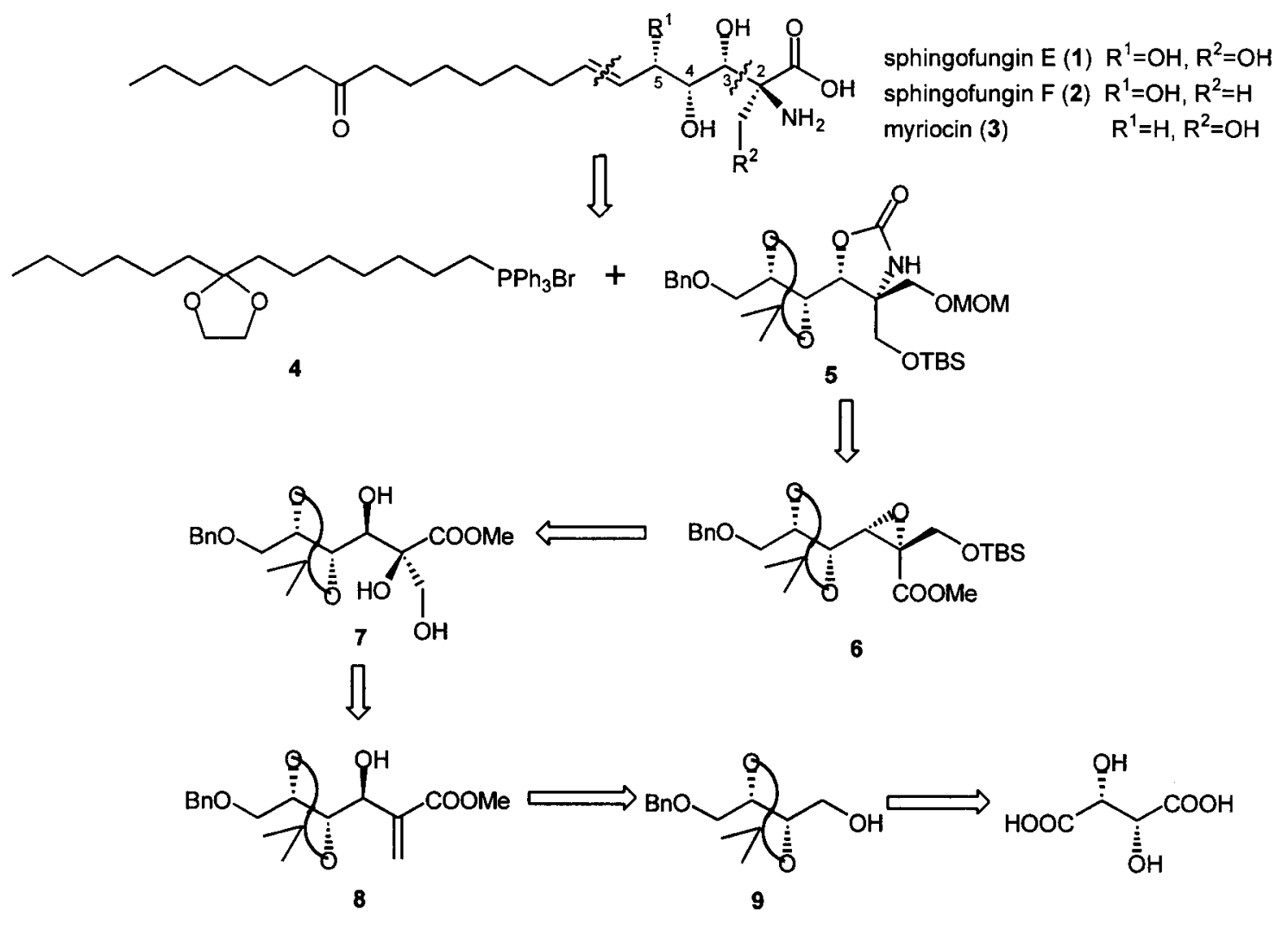

Scheme 1

Synlett 2001, SI, 904-906 ISSN 0936-5214 @ Thieme Stuttgart · New York 


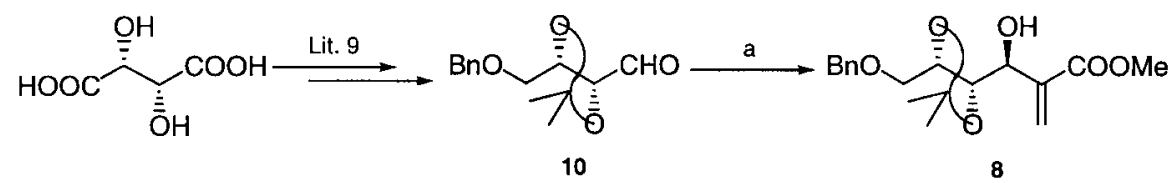

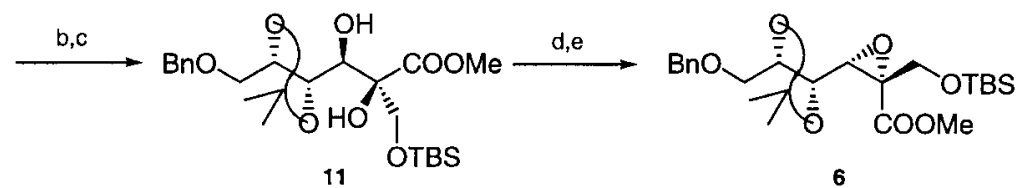

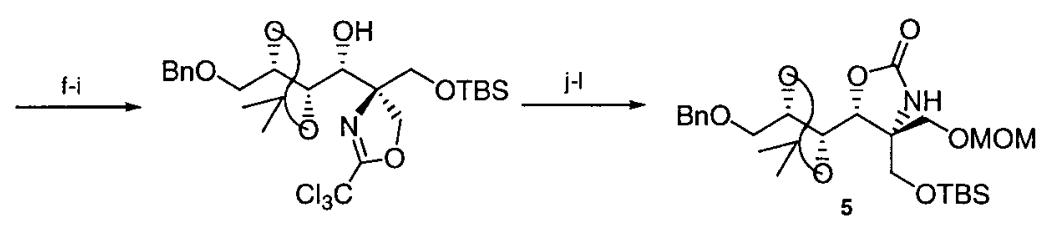

12

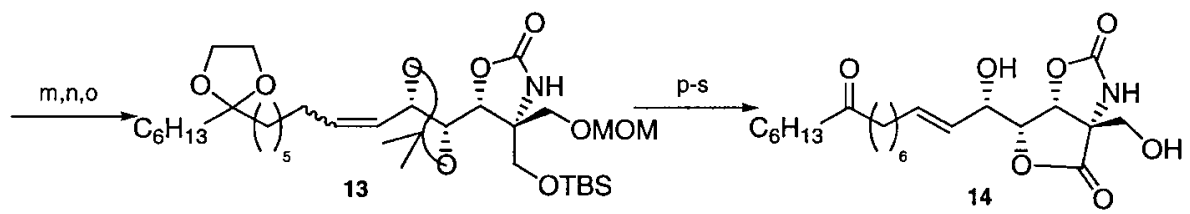

$\mathrm{t}$ sphingofungin $\mathrm{E}(\mathbf{1})$

Scheme 2 (a) methylacrylate, DABCO, rt, 70\%; (b) $\mathrm{OsO}_{4}, \mathrm{NMO}$, acetone- $\mathrm{H}_{2} \mathrm{O}$ (8:1), rt; (c) TBSCl, $\mathrm{Et}_{3} \mathrm{~N}$, cat. DMAP, 89\% (2 steps); (d) $\mathrm{MsCl}, \mathrm{Py}, \mathrm{CH}_{2} \mathrm{Cl}_{2}, 0^{\circ} \mathrm{C}$ to rt; (e) $\mathrm{K}_{2} \mathrm{CO}_{3}, \mathrm{MeOH}$, rt, $91 \%$ (2 steps); (f) DIBAL-H, $\mathrm{CH}_{2} \mathrm{Cl}_{2},-78{ }^{\circ} \mathrm{C}$; (g) $\mathrm{NaBH}_{4}, \mathrm{MeOH}^{\circ}{ }^{\circ} \mathrm{C}, 90 \%$ (2steps); (h) $\mathrm{Cl}_{3} \mathrm{CCN}$, DBU, $\mathrm{CH}_{2} \mathrm{Cl}_{2}, 0{ }^{\circ} \mathrm{C}$, (i) $\mathrm{Et}_{2} \mathrm{AlCl}, \mathrm{CH}_{2} \mathrm{Cl}_{2}, 0{ }^{\circ} \mathrm{C}, 97 \%$ (2steps); (j) $\mathrm{CO}\left(\mathrm{OCCl}_{3}\right)_{2}, \mathrm{Py}, \mathrm{CH}_{2} \mathrm{Cl}_{2},-35{ }^{\circ} \mathrm{C}$ to rt; $(\mathrm{k}) \mathrm{K}_{2} \mathrm{CO} \mathrm{O}_{3}, \mathrm{MeOH}^{\circ} 0{ }^{\circ} \mathrm{C}$, $81 \%$ (2steps); (l)MOMCl, ${ }^{i} \mathrm{Pr}_{2} \mathrm{NEt}, \mathrm{CH}_{2} \mathrm{Cl}_{2}$, reflux, 87\%; (m) $\mathrm{H}_{2}, \mathrm{Pd}(\mathrm{OH})_{2}$, EtOAc-MeOH (4:1); (n) $(\mathrm{COCl})_{2}, \mathrm{DMSO} \mathrm{CH}_{2} \mathrm{Cl}_{2}, \mathrm{Et}_{3} \mathrm{~N},-78{ }^{\circ} \mathrm{C}$ to rt; (o) 4, BuLi, THF, $-78{ }^{\circ} \mathrm{C}$ to rt, $60 \%$ (3 steps); (p) $h v$, PhSSPh, cyclohexane-dioxane (19:1) 95\%; (q) TBAF, THF, rt; (r) PDC, DMF, rt; (s) $\mathrm{TsOH}, \mathrm{EtOH}-\mathrm{H}_{2} \mathrm{O}$ (7:3), reflux, 77\% (3steps); (t) $1 \mathrm{~N} \mathrm{NaOH,} \mathrm{MeOH,} \mathrm{reflux,} \mathrm{then} \mathrm{neutralized} \mathrm{with} \mathrm{IRC-76,} 75 \%$.

derived from substrate-controlled dihydroxylation ${ }^{8}$ of Baylis-Hillman adduct $\mathbf{8}$ and subsequent regiospecific epoxide formation. This analysis led to L-(+)-tartaric acid as the ultimate starting material. Based on this consideration, it is conceivable that by simple replacement of tartaric acid by malic acid, the same reaction strategy would afford myriocin (3). Thus, our route was applicable to the synthesis of a number of $\alpha$-substituted serine derivatives, including other members and analogs of the sphingofungin family.

The total synthesis of $\mathbf{1}$ is represented in Scheme 2. Aldehyde $\mathbf{1 0}$ was prepared from L-(+)-tartaric acid according to literature. ${ }^{9}$ Baylis-Hillman reaction of $\mathbf{1 0}$ provided a convenient access to ester $\mathbf{8}$ with moderate diastereoselectivity (70:30). ${ }^{10}$ Taking advantage of substrate control, ${ }^{8}$ the dihydroxylation of $\mathbf{8}$ gave 2,3-syn-triol as the sole product, in which the primary hydroxyl group was protected as TBS ether. Then the secondary hydroxyl group in 11 was selectively mesylated and treated with $\mathrm{K}_{2} \mathrm{CO}_{3}$ to afford the ring closure product, epoxide $\mathbf{6}$. The ester part was then reduced to hydroxymethyl group which served as a tether for subsequent Hatakeyama reaction to give oxazoline 12 with complete inversion at $\mathrm{C}-2$. At this stage, all stereogenic centers had been efficiently established. 12 was then successively treated with triphosgene, ${ }^{12} \mathrm{~K}_{2} \mathrm{CO}_{3}$ and $\mathrm{MOMCl}$ to afford the cyclic carbamate 5. Debenzylation followed by Swern oxidation and Wittig reaction gave (Z)-13 predominantly. Isomerization of the double bond in 13 followed by desilylation and oxidation ${ }^{13}$ gave a carboxylic acid, which lactonized to afford bicyclic compound $\mathbf{1 4}$ with concomitant removal of ketal and MOM protection under acid catalysis. Finally, saponification of 14 and subsequent routine workup afforded sphingofungin E, the spectroscopic data of which are consistent with those reported in the literature. ${ }^{14}$

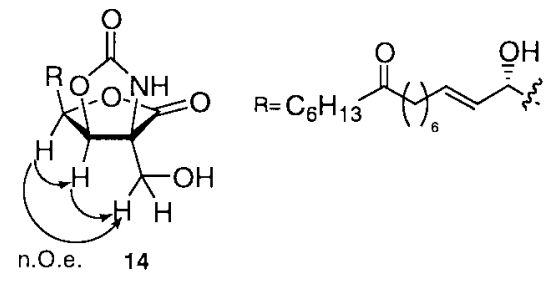

Scheme 3

As shown in Scheme 3, the absolute configurations of sphingofungin E was determined by NOESY experiment of lactone 14. Since the two chiral centers inherited from L-(+)-tartaric acid remained untouched during all synthetic steps, we reasoned that the stereochemistry of sphingofungin $\mathrm{E}$ is identical with that of sphingofungin $\mathrm{F}$, i.e. $(2 S$, $3 R, 4 R, 5 S, 6 E)$. 
In summary, the first total synthesis of sphingofungin $\mathrm{E}$ has been achieved in 19 steps and $8.1 \%$ overall yield from commercially available alcohol 9 derived from L-(+)-tartaric acid. Moreover, its stereochemistry has been determined. It is noteworthy that by simple change of starting material, myriocin and other structurally related substances could be obtained via the same route. The minor diastereomer of the Baylis-Hillman reaction would also provide an access to 2,3-epi-sphingofungin E. Moreover, utilization of the minor Baylis-Hillman adduct would render our synthesis of sphingofungin E into a diastereoconvergent one with further improvement of the overall yield. ${ }^{15}$ The details will be reported in due course.

\section{Acknowledgement}

We are grateful to the National Natural Science Foundation of China and the Major Basic Research Development Program (G2000077506) for financial support. One of us (B. W.) thanks Mr. Rob Hoen for proof reading.

\section{References and Notes}

(1) Horn, W. S.; Smith, J. L.; Bills, G.F.; Raghoobar, S. L.; Helms, G. L.; Kurtz, M. B.; Marrinan, J. A.; Frommer, B. R.; Thornton, R. A.; Mandala, S. M. J. Antibiot. 1992, 45, 1692.

(2) (a) Kluepfel, D.; Bagli, J.; Baker, H.; Charest, M. P.; Kudelski, A.; Sehgal, S. N.; Vezina, C. J. Antibiot. 1972, 25, 109. (b) Bagli, J.; Kluepfel, D. J. Org. Chem. 1973, 38, 1253. (c) Aragozzini, F.; Marachini, P. L.; Craveri, R. Tetrahedron 1972, 28, 5493. (d) Sasek, V.; Sailer, M.; Vokoun, J.; Musilek, V. J. Basic Microbiol. 1989, 29, 383. (e) Fujita, T. Inoue, K.; Yamamoto, S.; Ikumoto, T.; Sasaki, S.; Toyama, R.; Yoneta, M.; Hoshino, Y.; Okumoto, T. J. Antibiot. 1994, 47, 208.

(3) (a) Reference 2e. (b) Miyake, Y. Kozutsumi, Y.; Nakamura, S.; Fujita, T.; Kawasaki, T. Biochem. Biophys. Res. Commun. 1995, 211, 396.

(4) (a) Kobayashi, S.; Matsumura, M.; Furuta, T.; Hayashi, T.; Iwamoto, S. Synlett 1997, 301. (b) Kobayashi, S.; Furuta, T.; Hayashi, T.;Nishijima, M.; Hanada, K. J. Am.Chem. Soc. 1998, 120, 908. (c) Trost, B. M.; Lee, C. B. J. Am.Chem. Soc. 1998, 120,6818 .
(5) For the total synthesis of sphingofungin F, see: Liu, D.-G.; Wang, B.; Lin, G.-Q. J. Org. Chem. 2000, 65, 9114.

(6) (a) Sano, S.; Kobayashi, Y.; Kondo, T.; Takebayashi, M.; Maruyama, S.; Fujita, T.; Nagao, Y. Tetrahedron Lett. 1995, 36, 2097. (b) Payette, D. R.; Just, G. Can. J. Chem. 1981, 59, 269.

(7) Hatakeyama, S.; Matsumoto, H.; Fukuyama, H.; Mukugi, Y.; Irie, H. J. Org. Chem. 1997, 62, 2275.

(8) (a) Bernardi, A.; Cardani, S.; Scolastico, C.; Villa, R. Tetrahedron 1988, 44, 491. (b) Su, Z.; Tamm, C. Helv. Chim. Acta 1995, 78, 1278.

(9) (a) Mash, E. A.; Nelson, K. A.; Densen, S. V.; Hemperly, S. B. Org. Syn. 1990, 68, 92. (b) Mukaiyama, T.; Suzuki, K.; Yamada, T. Chem. Lett. 1982, 929.

(10) Separated by silica gel column chromatography.

(11) Drewes, S.; Khan, A. A.; Rowland, K. Synth. Commun. 1993, $23,183$.

(12) Schmidt, U.; Respondek, M.; Lieberknecht, A.; Werner, J.; Fisher, P. Synthesis 1989, 256.

(13) Corey, E. J.; Schmidt, G. Tetrahedron Lett. 1979, 399.

(14) $[\alpha]_{\mathrm{D}}{ }^{20}=-13^{\circ}(c=0.19$ and $0.30, \mathrm{MeOH}) ; \mathrm{mp} 147-149{ }^{\circ} \mathrm{C},{ }^{1} \mathrm{H}$ NMR $\left(300 \mathrm{MHz}, \mathrm{CD}_{3} \mathrm{OD}\right) \delta 0.89(\mathrm{t}, 3 \mathrm{H}, J=6.6 \mathrm{~Hz}), 1.25-1.60$ (m, 16H), 2.05 (q-like, 2H), 2.44 (t, 4H, $J=7.3 \mathrm{~Hz}), 3.65$ (d, $1 \mathrm{H}, J=7.1 \mathrm{~Hz}), 3.85,3.95\left(\mathrm{AB}, 2 \mathrm{H}, J_{\mathrm{AB}}=10.9 \mathrm{~Hz}\right), 3.96(\mathrm{~s}$, $1 \mathrm{H}), 4.10(\mathrm{t}, 1 \mathrm{H}, J=7.4 \mathrm{~Hz}), 5.44(\mathrm{dd}, 1 \mathrm{H}, J=15.4,7.6 \mathrm{~Hz})$, $5.77(\mathrm{dt}, 1 \mathrm{H}, J=15.3,6.6 \mathrm{~Hz}) ;{ }^{13} \mathrm{C}$ NMR $\left(\mathrm{CD}_{3} \mathrm{OD}\right) \delta 14.6$, 23.8, 25.2, 30.3, 30.4, 30.5, 33.0, 33.3, 43.8, 65.2, 70.7, 71.4, $75.8,76.4,130.5,135.9,173.3,214.6 ;$ IR $\left(\mathrm{cm}^{-1}\right) v=3122$, 2929, 1707, 1644, 1397, 1071, 724; ESI-MS 418.5(M+H).

(15) Bailey, M.; Staton, I.; Ashton, P. R.; Marko, I. E.; Ollis, W. D. Tetrahedron: Asymmetry 1991, 2, 495.

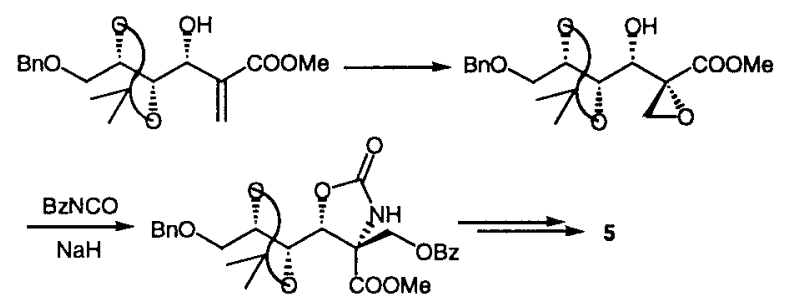

Article Identifier:

1437-2096,E;2001,0,SI,0904,0906,ftx,en;Y19400ST.pdf 